Uluslararası Sosyal Bilgilerde Yeni Yaklassımlar Dergisi,2020, 4(1), 151-164

International Journal of New Approaches in Social Studies, 2020, 4(1), 151-164

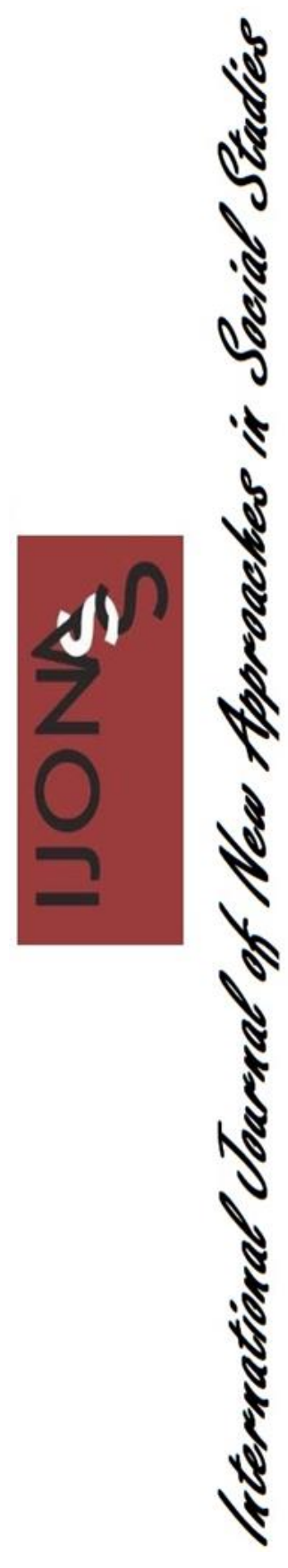

\title{
Probleme Dayalı Öğrenme Yaklaşımına İlişkin Fen Eğitimi Alanında Yapılan Bilimsel Çalışmaların İncelenmesi
}

\author{
Fatih Serdar YILDIRIM ${ }^{1 *} \&$ Serkan SAY ${ }^{2}$ \\ Gönderilme Tarihi:10 Haziran 2020 \\ Kabul Tarihi: 25 Haziran 2020 \\ DOI: $10.38015 /$ sbyy. 750758
}

\begin{abstract}
Öz:
Bu çalışma, ülkemizde fen ĕ̌itiminde probleme dayalı öğrenmeyi konu alarak yapılan çalışmaları belirlemek amacıyla literatür taraması yapılarak gerçekleştirilmiştir. Bu çalışma için 2010-2020 yılları arasında, Probleme Dayalı Öğrenme (PDÖ) yaklaşımında fen eğitimi alanında yayınlanmış çalışmalar belirlenen kriterler doğrultusunda incelemeye alınmıştır. Bu çalışma kapsamında incelenen tüm yayınlar; yayın türü, seçilen örneklem grubu, araştırma yöntemi, ele alınan ünite ve konu, araştırmada tercih edilen veri toplama araçlart ve yayın yılı gibi kriterlere göre değerlendirilmiştir. Çalışmada probleme dayalı öğrenme yaklaşımında 40 yüksek lisans tezi,15 doktora tezi ve 29 makale bu incelemeye dahil edilmiştir. Çalışmada nitel araştırma yöntemlerinden biri olan doküman incelemesiyle veriler toplanmıştır. Verilerin analizi için betimsel analiz kullanılarak yüzde, frekans hesaplamaları yardımı ile analiz gerçekleştirilmiştir. Çalışmanın sonucunda; probleme dayalı ögrenme ile ilgili yapılan yayınlarda en çok tercih edilen yöntemin nicel araştırma olduğu, yayın türü çeşidi olarak en fazla yüksek lisans tezleri ardından makale çalışmalarının yapıldı ̆̆ en az ise doktora tezlerinin yürütüldü̈̆̈̈ tespit edilmiştir. PDÖ çalışmalarında çalışma grubu olarak ortaokul öğrencilerinin ardından lisans ĕgitimi alan ögrencilerle araştırmaların yürütüldüğ̈̈ belirlenmiştir. Ölçme aracı olarak ise başarı testi ve tutum ölçeğinin daha yoğun kullanıldığ ancak farklı birçok veri toplama aracının tercih edildiği sonucuna varılmıştır.
\end{abstract}

Anahtar Kelimeler: Probleme dayalı öğrenme, fen eğitimi, eğitim yaklaşımları.

\begin{abstract}
:
This study has been carried out in order to determine the studies conducted in science education in our country on the basis of problem-based learning. For this study, in the field of problem based learning for science education; studies published between 2010 202 on science education have been scrutinized in line with the determined criteria. All the publications reviewed within the scope of this study have been examined in line with the criteria such as the type of publication, sample group selected, research method, the unit and subject treated, data collection tools preferred in the research and the year of publication. 40 master's theses, 15 dissertations and 29 essay written on the subject of problem based learning approach have been taken into consideration. In the study, data was collected through document analysis, which is one of the qualitative research methods. For the analysis of data, descriptive analysis method is utilized and the process is completed with the help of percentage and frequency calculations. As a result of the study, it is observed that while quantitative research method is the most common method
\end{abstract}

\footnotetext{
${ }^{1}$ Akdeniz Üniversitesi, Türkiye. Orcid ID: 0000-0003-4080-8488

${ }^{2}$ Mersin Üniversitesi, Türkiye. Orcid ID: 0000-0002-0917-8660

*Sorumlu Yazar (Corresponding Author): fsyildirim@akdeniz.edu.tr
} 
for the publications made on the subject of problem based learning and while most of the publications made on this field are master's theses, essays are the second most common type and dissertations are the last. It is observed that while secondary school students were the most preferred study group in problem-based learning studies, graduate students were also often chosen as a sample group. It was concluded that while success tests and attitude scales were used more frequently as measurement tools, various data collection tools are preferred.

Keywords: Problem based learning, science education, education approaches.

\section{GíRiş}

Fen bilimleri günlük yaşantımızın içerisinde yer almaktadır. Öğrenciler öğrendiği bilgileri yaşamları içerisinde kullanarak karşılaştıkları sorunlara çözüm üretebilmektedirler. Fen eğitiminde öğrencilerin hâkim olduğu ve öğretmenlerin rehber olduğu yaklaşımlar daha hâkim olmaya başlamıştır (Söyleyici, 2018). Bu yaklaşımlar arasında probleme dayalı öğrenme (PDÖ) yer almaktadır. Probleme dayalı öğrenmenin gerçekleştirilebilmesi için takip edilmesi gereken adımlar şunlardır; 1)Problemi açıklamak için içerisinde yer alan bilinmeyen kavramları ifade etme, 2)Problemin açıklamasını yapma ve ifade edilecek kavramları listelendirme, 3)Problemi irdeleme, düşündürme, ön bilgileri kullanıp var olan kavramlar hakkında yorumlama yapma,4)Probleme ilişkin öne sürülen düşünceleri inceleme ve ilerleyişin birbirleriyle bağlantılı olarak sürmesini sağlama, 5)Öğrencilerin bireysel öğrenmelerini sağlamak için konuları formülize etme, 6) Elde edilen sonuçları gruplar arasında paylaşım yapma ve açıklanan terimleri var olan sonuçlarla bağdaştırmaya çalışma (Lehtinen, 2002).

Probleme dayalı öğrenmede öğrencilerin ortaya çıkan problemlere yönelik çözüm üretebilmeleri için kullanabilecekleri yöntemleri öğretmektedir (Aysu, 2019). PDÖ öğrenmede, merkezde öğrenci yer almaktadır. Öğrenciler gruplar halinde çalışarak, öğretmenin yönlendirmesiyle çözüme ulaşmaları sağlanmaktadır. Aynı zamanda öğrencilerin sorgulama ve eleştirme yapma yetenekleri gelişmektedir. Öğrencilerin bilgileri kendilerinin öğrenmelerinin sağlandığı ortamlar oluşturulmaktadır Barrows (1996) Probleme dayalı öğrenme de öğrencilere basit olmayan daha komplike bir durum verilerek, öğrencilere içinde bulundukları bu durumu içselleştirmenin sorumluluğunu yüklenir (Çiftçi, Ektem ve Meydan 2005). Probleme dayalı öğrenmede, kullanılan problem oldukça önemlidir. Bu problemlerin türleri; iyi yapılandırılmış ve iyi yapılandırılamamış olarak gruplandırılmaktadır. Uluyol (2009) iyi yapılandırılmış problemler; öğretmenin verdiği yol haritası ile öğrenciler sonuca ulaşır, birden fazla çözümü yoktur tek bir cevabı vardır, problemle ilgili bütün gerekli bilgiler öğrencilere aktarılır (Şahin, 2011). İyi yapılandırılmamış problemler ise; tek bir çözümü olmayan birden fazla sonucu ya da herhangi bir çözümü olamayabilir, değerlendirme sürecinde birçok kriter olabilir, öğrencilerin kendi. Düşündükleri ve savundukları durumların arkasında durmaları beklenmektedir. Öğrenme sırasında seçilen günlük yaşamın içinden tercih edileceği için öğrencilerin istekleri artmaktadır. (Jonassen, 1997; Aktaran: Şendağ, 2008).

Probleme dayalı öğrenmede nitelikli bir problemin özellikleri şu şekilde sıralanmıştır: Saban (2000) ve Kılınç'a göre (2007);

- Öğrencilerin dikkatlerini çekmeli, problemi çözmeye istek uyandırmalıdır.

- Öğrencilerin içinde ulunduğu yaşamlarından parçalar barındırmalıdır.

- Grup halinde çözülen problemler için herkesin söz sahibi olabileceği problem durumları seçilmelidir.

- Cevabı herkes tarafindan kabul görmüş problemler olmamalıdır. 
- Öğrencilerin hazırbulunuşlukları ön planda olacak şekilde belirlenmelidir.

PDÖ 'nün karşılaştıkları problemlere çözüm bulabilme yeteneklerini büyük ölçüde geliştirdiğini, öğrenci profilinin sınıf içerisinde aktif rol aldığı ortaya çıkmıştır (Kaptan ve Korkmaz, 2001). Günümüzde artık eğitim sisteminde aktif öğrenmenin kuramsal temellerinden olan yapılandırmacı anlayışa dayanmakta olan Probleme dayalı öğrenme (PDÖ) yapısalcı öğrenme - öğretme anlayışının en önemli uygulamalarındandır. Öğrenenlerin fen derslerinde kavradıkları bilgi ve becerileri günlük yaşamlarına taşıyabilmeleri ve karşılarına çıkan yeni problemleri çözebilmeleri için kullanabilecekleri bir yaklaşım olarak değerlendirilmektedir. $\mathrm{Bu}$ anlamda eğitim sisteminde önemli olan bu yaklaşımın getirilerinden yola çıkılarak; PDÖ ile ilgili yapılmış çalışmaların betimsel analizle incelenmesi ve bunun incelemenin sonunda elde edilecek olan sonuçlar bundan sonra bu alanda çalışacak olan kişilere yeni kapılar açabilecek aynı zamanda konu içeriği hakkında bilgi sahibi olabilmelerine fırsat tanıyacaktır (Temel, Şen ve Y1lmaz, 2014).

$\mathrm{Bu}$ araştırmada; probleme dayalı öğrenme (PDÖ) ile ilgili 2010-2020 yılları arasında yayınlanmış YÖK Ulusal tez merkezinde, TR dizin ve Google Scholar veri tabanlarında yer alan yüksek lisans, doktora tezleri ve makaleleri aşağıda yer alan kriterler doğrultusunda incelemeye alınmıştır. $\mathrm{Bu}$ inceleme fen bilimler ve alt birimleri olan fizik, kimya biyoloji eğitimi alanlarında PDÖ yaklaşımı ile ilgili yapılmış olan çalışmaları içermektedir. Bahsi geçen kriterler; çalışmaların yayın türü, örneklem grubu, araştırma yöntemi, ele alınan ünite ve konu, tercih edilen veri toplama araçları yıllara göre incelenmiştir. Çalışma da aşağıdaki sorulara cevap aranmiştır:

$\mathrm{Bu}$ alanda yapılmış çalışmaların;

1. Yayın türüne göre dağılımı nasıldır?

2. Yayın türü ve yıllara göre dağılımı nasıldır?

3. Araştırma yöntemine göre dağılımı nasıldır?

4. Yayın türü ve araştırma yönteminin yıllara göre dağılımı nasıldır?

5. Araştırma yöntemlerinin yıllara göre dağılımı nasıldır?

6. Yayın türü ve örneklem grubuna göre dağılımı nasıldır?

7. Yayın türüne ve veri toplama aracına göre dağılımı nasıldır?

8. Yayın türüne, örneklem grubuna ve çalışılan konuya göre dağılımı nasıldır?

\section{Araştırmanın Sinırlılı̆̆ı}

Bu çalışmada fen bilimler ve fizik, kimya, biyoloji alanlarında PDÖ ile ilgili çalışmalar incelemeye dahil edilmesiyle sınırlıdır. 2010-2020 yılları arasında yayınlanmış olan çalışmalarla sınırlıdır. Bunun yanı sıra 2020 yılının tamamlanmamış olması da çalışmanın sinırlılığına dahil edilebilir.

\section{YÖNTEM}

\section{Araştırma Modeli}

Çalışmada nitel araştırma desenlerinden biri olan doküman incelemesi kullanılmıştır. Doküman incelemesi, araştırılması hedeflenen olgu ya da olaylar hakkında bilgi içeren yazılı materyallerin analizini kapsamaktadır (Yıldırım ve Şimşek, 2013). Doküman incelemesi daha 
kısa sürede verilere ulaştırdığı için diğer yöntemlere göre tercih edilirliğini artırmaktadır (Koyuncu, Şata ve Karakaya, 2018).

\section{Veri Toplama Süreci}

Çalışmanı evrenini fen alanında 2010-2020 yılları içerisinde Probleme Dayalı öğrenme Yaklaşımını benimsemiş ve yayınlanmış doktora tezi, yüksek lisans tezi ve makaleler oluşturmaktadır. Yüksek lisans, doktora tezleri, makalelere ait verilere ulaşmak için Ulusal Tez Merkezi, TR Dizin, ULAKBIMM ve Google Scholar veri tabanlarından ulaşılmıştır. Bu veri tabanlarında arama yaparken 'probleme dayalı fen eğitimi ', 'problem temelli ögrenme' ve 'probleme dayalı öğrenme' şeklinde kelimeler aratılarak sonuçlara ulaşılmıştır. Bu arama sonucunda 40 yüksek lisans tezi,15 doktora tezi ve 29 makale araştırmada incelemeye alınmıştır. Seçilen makalelerin yüksek lisans ve doktora tezlerinden oluşmayanlar dahil edilmiştir.

\section{Verilerin Analizi}

Araştırmada verilerin analizinde betimsel analiz ile gerçekleştirilmiştir. Betimsel analiz elde edilen verilerin formunda değişiklik yapmadan doğrudan aktarımla ilgili kişilere sunulma biçimidir (Walcott ,1994). Ayrıca betimsel analiz daha önceden hazırlanmış olan kriterlere göre verilerin incelenmesi, tanımlamalarının yapılması ve elde edilen sonuçların yorumlanması amaçları doğrultusunda yapıla bir analizdir (Yıldırım ve Şimşek 2013). Bu araştırmada da betimsel analiz ile verilerin analizi gerçekleştirilmiştir. Verilerin analizi yapıldıktan sonra frekans ve yüzde hesaplamaları yapılarak sonuçlara ulaşılmış, bu sonuçlar yayın yılı, örneklem grubu, yöntemi ve yayın türü, konu şeklinde kategorize edilerek tablo ve grafiklerle desteklenmiştir.

\section{BULGULAR}

Elde edilen veriler yayın türü, yayın yılı, araştırma yöntemine, örneklem grubuna, islenen ünite ve konuya ve ölçme aracı türüne göre analizi yapılmıştır. Elde edilen sonuçlar frekans ve yüzde değerleri ile birlikte görselleştirilerek yorumu yapılmıştır.

Şekil 1 incelendiğinde burada PDÖ yaklaşımı üzerine çalışılmış yayın türlerinin yüzdelik dağılımı görülmektedir.

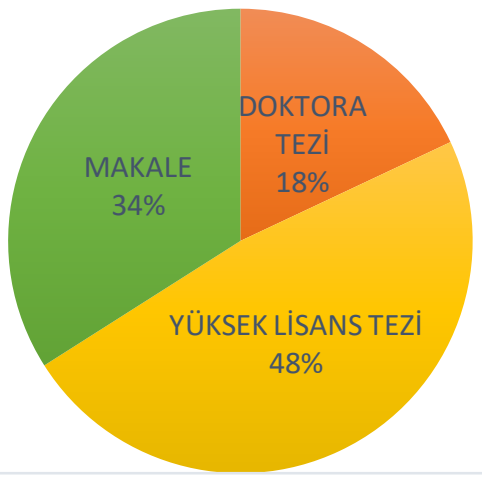

Şekil 1. PDÖ yaklaşımı ile ilgili yayın türleri 
Probleme Dayalı Öğrenme yaklaşımına ilişkin çalışmaların \%18'nin doktora tezi, \%48' inin yüksek lisans tezi ve \%34 'ünün makale olduğu görülmektedir. Bu alanda en fazla yüksek lisans tezleri, en az ise doktora tezlerinin yapıldı̆̆

Şekil 2 incelendiğinde PDÖ ile ilgili yapılmış olan çalışmaların yayın yılına ve türüne göre yüzdelik dağılımı gösterilmektedir.

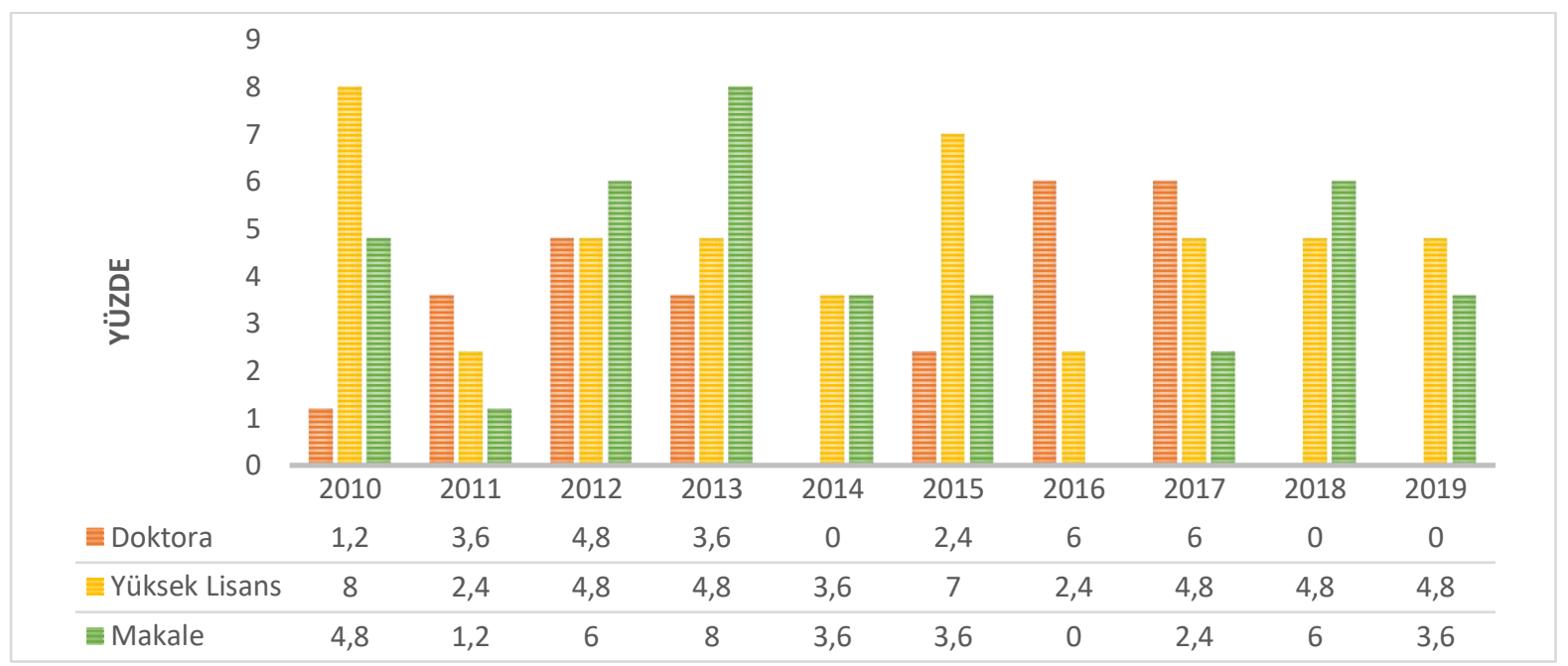

Şekil 2. PDÖ ile İlgili yapılmış, olan çalışmaların yayın türü ve yıllara göre yüzdelik dağılımı

Şekil 2 incelendiğinde PDÖ’ ye ilişkin yapılmış doktora tez çalışmalarının en fazla 2016 (\%6) ve 2017 (\%6) ve hiç çalışmanın yapılmadığ yıllar ise 2014,2018 ve 2019 yıllarının olduğu belirlenmiştir. Yüksek lisans tezi çalışmalarının en fazla olduğu 2010 (\%8), en az olduğu 2011 (\%2.4) ve 2016 (\%2.4) yılları olarak tespit edilmiştir. Makale çalışmalarının en fazla olduğu yıl $2013(\% 8), 2016$ yılı hiç yayın yapılmadığı yıl olarak saptanmıştır. 2010 ve 2013 yıllarında PDÖ’ ye ilişkin yayınların en fazla olduğu belirlenmiştir.

Şekil 3 incelendiğinde yayın türlerinde tercih edilen araştırma yöntemleri nicel, nitel ve karma şeklinde sınıflandırılarak tablolaştırılmıştır.

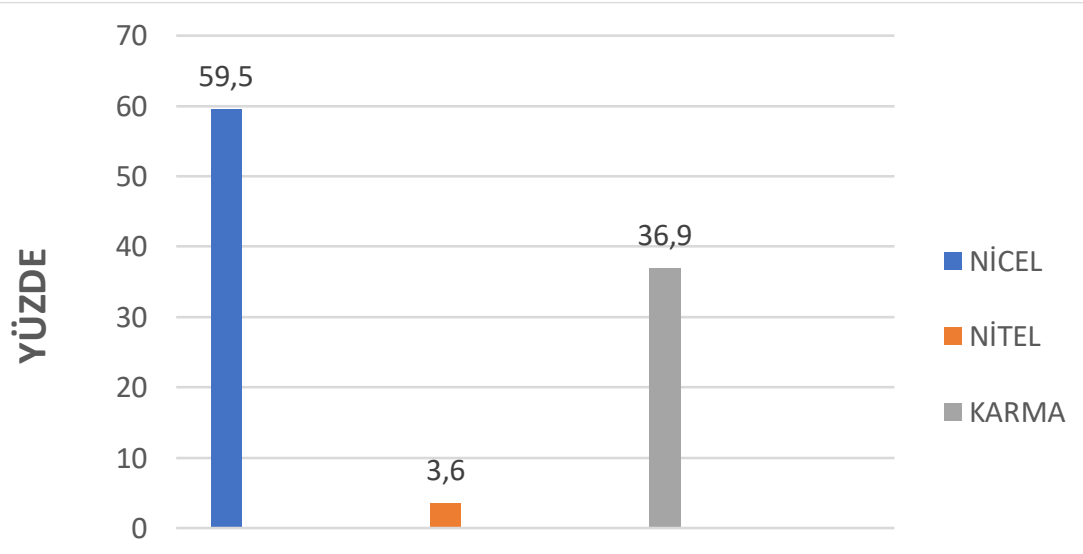

ARAŞTIRMA YÖNTEMLERi

Şekil 3. PDÖ ile ilgili yapılmış, olan çalışmaların araştırma yöntemine göre dağılımı 
Yayın türlerinde en çok araştırma yöntemi olarak nicel yöntem, bunu takiben karma yöntem, en az ise nitel yöntem tercih edilmiştir. \%59.5 nicel yöntem, \%36.9 karma yöntem ve \%3.6 ile nitel araştırma yönteminin kullanıldı̆̆ görülmektedir.

Tablo 1'de, yayın türü ve araştırma yönteminin yıllara göre dağılımı gösterilmektedir.

Tablo 1. Yayın türü ve tercih edilen yöntem türlerinin yıllara göre dağılımı

\begin{tabular}{lccccccccc}
\hline \multirow{2}{\text{Yillar}}{} & $\begin{array}{c}\text { Makale } \\
\text { f }\end{array}$ & $\begin{array}{c}\text { YL } \\
\text { f }\end{array}$ & $\begin{array}{c}\text { Doktora } \\
\text { f }\end{array}$ & $\begin{array}{c}\text { Makale } \\
\text { f }\end{array}$ & $\begin{array}{c}\text { YL } \\
\text { f }\end{array}$ & $\begin{array}{c}\text { Doktora } \\
\text { f }\end{array}$ & $\begin{array}{c}\text { Makale } \\
\text { f }\end{array}$ & $\begin{array}{c}\text { YL } \\
\text { f }\end{array}$ & $\begin{array}{c}\text { Doktora } \\
\text { f }\end{array}$ \\
\hline $\mathbf{2 0 1 0}$ & 3 & 7 & - & 1 & - & - & - & - & 1 \\
$\mathbf{2 0 1 1}$ & 1 & 2 & 2 & - & - & - & - & - & 1 \\
$\mathbf{2 0 1 2}$ & 4 & 3 & - & - & - & - & 1 & 1 & 4 \\
$\mathbf{2 0 1 3}$ & 5 & 3 & - & - & - & - & 2 & 1 & 3 \\
$\mathbf{2 0 1 4}$ & 1 & 2 & - & - & - & - & 2 & 1 & - \\
$\mathbf{2 0 1 5}$ & 2 & 5 & 1 & - & - & - & 1 & 1 & 1 \\
$\mathbf{2 0 1 6}$ & - & 1 & 1 & - & - & - & - & 1 & - \\
$\mathbf{2 0 1 7}$ & 2 & 1 & - & - & - & - & - & 3 & 1 \\
$\mathbf{2 0 1 8}$ & - & 1 & - & - & - & - & 1 & 3 & - \\
$\mathbf{2 0 1 9}$ & 1 & 2 & - & 2 & - & - & - & 2 & - \\
\hline $\mathbf{f}$ & $\mathbf{1 9}$ & $\mathbf{2 7}$ & $\mathbf{4}$ & $\mathbf{3}$ & - & - & $\mathbf{7}$ & $\mathbf{1 3}$ & $\mathbf{1 1}$ \\
$\mathbf{\%}$ & & $\mathbf{5 9 . 5}$ & & & $\mathbf{3 . 6}$ & & & $\mathbf{3 6 . 9}$ & \\
\hline
\end{tabular}

(YL=Yüksek Lisans)

Şekil 3'te yayın türlerinde tercih edilen yöntemlerin yüzdelik olarak dağılımı ifade edilmiști. Tablo 1'de ise bu tercih edilen yöntemlerin yayın türlerine göre yıllara dağılımı ifade edilmeye çalışılmıştır. Tablo incelendiğinde tercih edilme isteğine göre en fazla nicel yöntem $\% 59,5$ oranıyla, daha sonra ise \%36,9 oranla karma yöntem gelmektedir. Nicel yöntemin en fazla tercih edildiği yılın 2010 ( $\mathrm{f}=10)$ olduğu tespit edilmiştir. Detaylı inceleme yapıldığında nicel yöntemi en çok tercih eden yayın türünün yüksek lisans tezleri $(\mathrm{f}=27)$ olduğu belirlenmiştir. Bunu takiben diğer yayın türünün makale $(\mathrm{f}=18)$ olduğu görülmüştür. Nitel yöntemin yalnızca makalelerde ( $\mathrm{f}=3$ ) tercih edildiği de tespit edilmiştir. Karma yöntemin en çok tercih edildiğ $i$ yayın türü yüksek lisans tezleri $(\mathrm{f}=13)$ olarak saptanmıştır. Yüksek lisans tezlerinde karma yöntemin tercih edilmeye başlaması 2012 yılı ve sonrası itibari ile geçerli olduğu görülmektedir. Nitel araştırma yöntemi yalnızca makalelerde kullanıldığı saptanmıştır.2010 ve 2019 yıllarında hazırlanan makalelerde bu yöntemin tercih edildiği saptanmıştır.

Şekil 4'te yapılan yayın türlerinde kullanılan yöntemlerin yıllara göre değişimleri gösterilmektedir. 


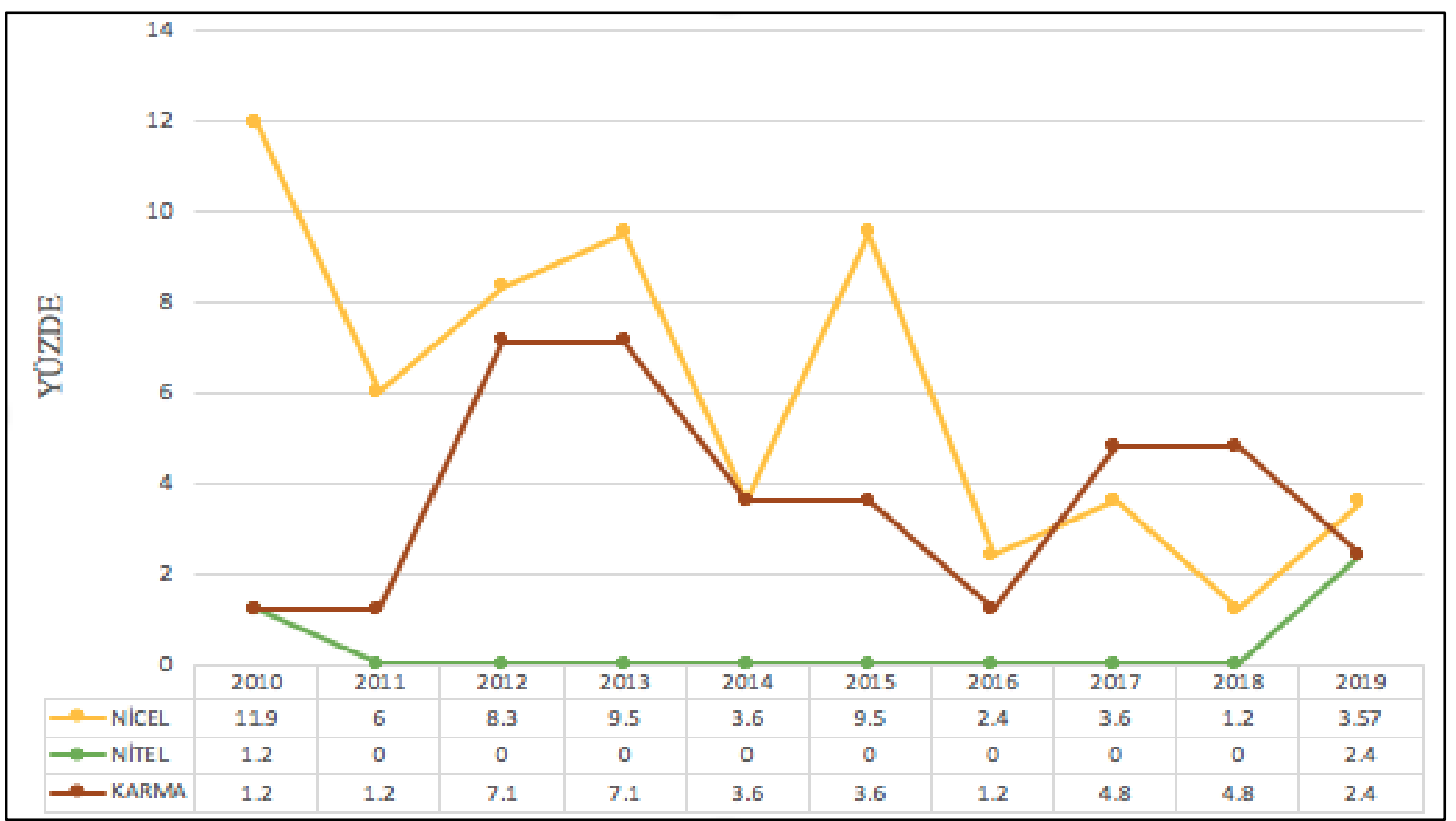

Şekil 4. Araştırma yöntemlerinin yıllara göre dağılımı

Tablo 1 'de yayın türleri ve yıllara göre dağılımı ifade edilmişti. Şekil 4'de ise bu yöntemlerin artış ve azalışlarını, yıllara göre dağılımlarını göstermek amacıyla oluşturulmuştur. Şekil 4 incelendiği zaman en çok tercih edilen yöntemin 2010 yılında (\%12) nicel araştırma yöntemi olduğu görülmektedir. Nitel araştırma yöntemi 2010 ve 2019 yıllarında artış göstermiş, bu yıllar haricinde herhangi bir çalışmada tercih edilmediği tespit edilmiştir. Karma araştırma yönteminin en çok tercih edildiği yıllar 2012 ve 2013 olarak saptanmıştır.

Şekil 5'de yayın türleri ve yayın türlerindeki örneklem grup dağılımları gösterilmektedir.

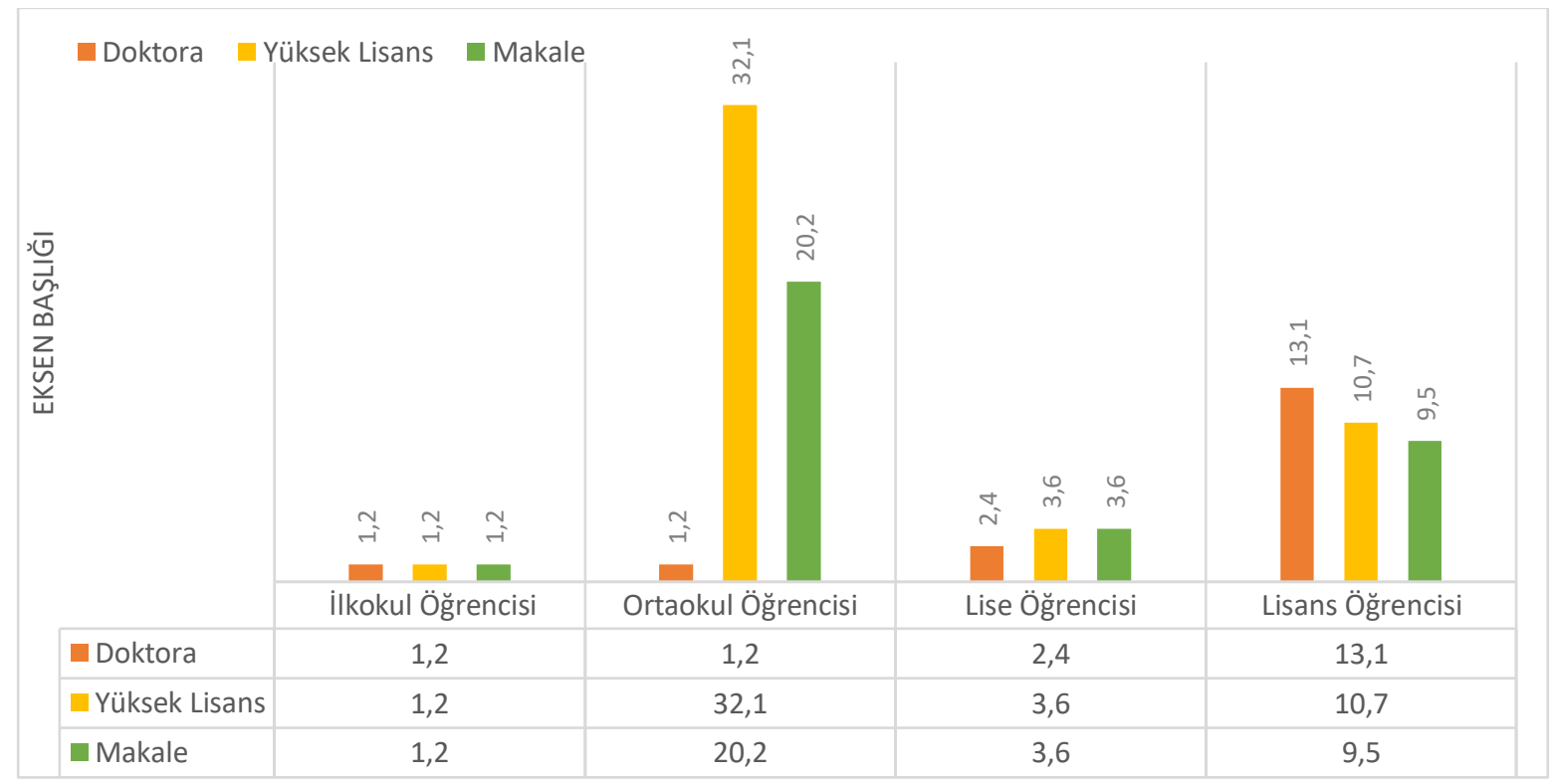

Şekil 5. Yayın türü - örneklem grubu dağılımı 
Şekil 5 incelendiği zaman en fazla çalışılan grubun ortaokul öğrencilerinin (\%53.5) oluşturduğu görülmektedir. Daha sonra lisans öğrencileri üzerinde çalışmaların yapıldığı saptanmıştır (\%33.3). En az tercih edilen grup ise ilkokul öğrencilerinin olduğu görülmektedir. Makale ve yüksek lisans yayın türünde en çok tercih edilen grup ortaokul öğrencilerini oluşturulduğu lisans öğrencilerinin ağırlıklı olarak doktora çalışmalarında seçildiği tespit edilmiştir.

Tablo 2. Yayın türü- veri toplama araçlarına göre dağılımı

\begin{tabular}{|c|c|c|c|c|c|}
\hline \multirow{2}{*}{ Veri Toplama Aracı } & \multirow{2}{*}{$\begin{array}{l}\mathbf{M} \\
\mathbf{f}\end{array}$} & \multirow{2}{*}{$\begin{array}{l}\mathbf{Y} \\
\mathbf{f}\end{array}$} & \multirow{2}{*}{$\begin{array}{l}\mathbf{D} \\
\mathbf{f}\end{array}$} & \multicolumn{2}{|c|}{ Toplam } \\
\hline & & & & $\mathbf{f}$ & $\%$ \\
\hline Başarı Testi & 12 & 26 & 10 & 48 & 21 \\
\hline Tutum Ölçeği & 11 & 25 & 6 & 42 & 18.4 \\
\hline Bilimsel Süreç Becerileri Ölçeği & 1 & 7 & 1 & 9 & 3,9 \\
\hline Kavram Testi & 3 & 10 & 6 & 19 & 8 \\
\hline Motivasyon Ölçeği & 8 & 4 & 2 & 14 & 6,1 \\
\hline İlgi Ölçeği & 1 & 1 & 2 & 4 & 1,8 \\
\hline Algı Ölçeği & 1 & 3 & 1 & 5 & 2,2 \\
\hline Görüşme & 9 & 11 & 8 & 28 & 12,3 \\
\hline Problem Senaryosu & 2 & 5 & 6 & 13 & 5,7 \\
\hline PDÖ’ye özgü ölçekler & 1 & 5 & 3 & 9 & 3,9 \\
\hline Gözlem & - & 1 & 4 & 5 & 2,2 \\
\hline Problem Çözme Envanteri & 1 & - & 2 & 3 & 1,3 \\
\hline Bilimsel İşlem Testi & 1 & 2 & 1 & 4 & 1,8 \\
\hline Davranış Testi & 1 & 1 & 1 & 3 & 1,3 \\
\hline Rubrik & - & 1 & 6 & 7 & 3,1 \\
\hline Akademik Risk Alma Ölçeği & - & 1 & - & 1 & 0,4 \\
\hline Açık Uçlu Sorular & 1 & - & - & 1 & 0,4 \\
\hline Yaratıcı Düşünme Testi & 2 & - & - & 2 & 0,9 \\
\hline Bilişötesi Farkındalık ölçeği & 2 & - & - & 2 & 0,9 \\
\hline Öz yeterlilik Testi & 1 & - & - & 1 & 0,4 \\
\hline Sosyal Beceri Ölçeği & 1 & - & - & 1 & 0,4 \\
\hline Doküman İnceleme & - & - & 3 & 3 & 1,3 \\
\hline Eleştirel Düşünme Ölçeği & - & - & 4 & 4 & 1,8 \\
\hline
\end{tabular}

(M: Makale, Y: Yüksek Lisans Tezi, D: Doktora Tezi)

Tablo 2 incelendiğinde veri toplama aracı olarak 48 çalışmada başarı testinin, 42 çalışmada tutum ölçeğinin, 28 tanesinde görüşme ve 19 tanesinde kavram testinin kullanıldığ 1 görülmektedir. Çalışmalarda motivasyon ölçeği, problem senaryosu, bilimsel süreç becerileri ölçeği ve PDÖ’ ye özgü ölçekler veri toplama aracı olarak tercih edilmektedir. Tabloda geriye kalan veri toplama araçları daha az sıklıkla tercih edildiği görülmektedir. Bu araçlar; ilgi ölçeği, alg1 ölçeği, gözlem, problem çözme envanteri, bilgi işlem testi, davranış testi, rubikler, akademik risk alma ölçeği, açık uçlu sorular, yaratıcı düşünme testi, bilişötesi farkındalık testi, öz yeterlilik testi, sosyal beceri ölçeği, doküman incelemesi ve eleştirel düşünme ölçeği şeklindedir. 
Tablo 3. Araştırmada yer alan çalışmaların yayın türleri, örneklem grupları ve çalıştıkları konulara göre dağılımı

\begin{tabular}{|c|c|c|c|c|c|c|}
\hline \multirow{2}{*}{$\begin{array}{l}\text { ÖRNEKLEM } \\
\text { GRUBU }\end{array}$} & \multirow{2}{*}{ KONU } & \multirow{2}{*}{$\begin{array}{l}\mathbf{M} \\
\mathbf{f}\end{array}$} & \multirow{2}{*}{$\begin{array}{l}\mathbf{Y} \\
\mathbf{f}\end{array}$} & \multirow{2}{*}{$\begin{array}{l}\text { D } \\
\mathbf{f}\end{array}$} & \multicolumn{2}{|c|}{ TOPLAM } \\
\hline & & & & & $\mathbf{f}$ & $\%$ \\
\hline \multirow[b]{2}{*}{ 4.sinif } & \multirow{2}{*}{$\begin{array}{l}\text { Işık ve Ses } \\
\text { Canlılar ve Yaşam }\end{array}$} & - & 1 & - & 1 & 2,5 \\
\hline & & 1 & - & - & 1 & \\
\hline \multirow{7}{*}{ 5.Sinıf } & Isı ve Sicaklık & - & 1 & - & 1 & \multirow{7}{*}{8.6} \\
\hline & Kuvvetin Ölçülmesi ve Sürtünme & - & 1 & - & 1 & \\
\hline & Vücudumuzun Bilmecesini Çözelim & - & 1 & - & 1 & \\
\hline & Enerji & - & 1 & - & 1 & \\
\hline & Iş1k ve Ses & - & 1 & - & 1 & \\
\hline & \multirow{2}{*}{$\begin{array}{l}\text { Işığın Yayılması } \\
\text { Belirtilmemiş }\end{array}$} & - & 1 & - & 1 & \\
\hline & & 1 & - & - & 1 & \\
\hline \multirow{7}{*}{ 6.sınıf } & Madde ve Isı & 3 & 4 & 1 & 8 & \multirow{7}{*}{24.7} \\
\hline & Maddenin Tanecikli Yapısı & 1 & 2 & 1 & 4 & \\
\hline & Yaşamımızdaki Elektrik & 2 & 1 & - & 3 & \\
\hline & Bitkiler ve Hayvanlarda Üreme, & - & 1 & - & 1 & \\
\hline & Büyüme, Gelişme & - & 1 & - & 1 & \\
\hline & Kuvvet ve Hareket & - & 1 & - & 1 & \\
\hline & $\begin{array}{l}\text { Fiziksel ve Kimyasal Değişimler } \\
\text { Vücudumuzdaki Sistemler }\end{array}$ & 2 & - & - & 2 & \\
\hline \multirow{7}{*}{ 7.sinıf } & İnsan ve Çevre & - & 3 & - & 3 & \multirow{7}{*}{14.9} \\
\hline & Vücudumuzdaki Sistemler & 1 & 1 & - & 2 & \\
\hline & Karışımlar & - & 1 & - & 1 & \\
\hline & Iş1k & 1 & 1 & - & 2 & \\
\hline & \multirow{3}{*}{$\begin{array}{l}\text { Kuvvet ve Enerji } \\
\text { Denetleyici ve Düzenleyici Sistemler } \\
\text { Belirtilmemiş }\end{array}$} & - & 2 & - & 2 & \\
\hline & & - & 1 & - & 1 & \\
\hline & & 1 & - & - & 1 & \\
\hline \multirow{3}{*}{ 8.sinif } & Kuvvet ve Hareket & - & 1 & - & 1 & \multirow{3}{*}{5} \\
\hline & Maddenin Halleri ve Isı & 1 & 1 & - & 2 & \\
\hline & Kalitım & 1 & - & - & 1 & \\
\hline \multirow[t]{2}{*}{ 9.sinif } & Elektrik ve Manyetizma & - & - & 1 & 1 & \multirow[b]{2}{*}{2.5} \\
\hline & Biyoloji & - & - & 1 & 1 & \\
\hline \multirow[t]{2}{*}{ 10.sinif } & Karışımlar & 1 & 2 & - & 3 & \\
\hline & Gazlar & 1 & - & - & 1 & 5 \\
\hline 11.sınıf & Kimyasal Denge & - & 1 & - & 1 & \\
\hline & Biyoloji & 1 & - & - & 1 & 2.5 \\
\hline & Yüzey Gerilimi & - & 1 & - & 1 & \\
\hline & Laboratuvar & 1 & 5 & - & 6 & \\
\hline & Kimyasal Kinetik & - & 1 & - & 1 & \\
\hline & Genel Fizik & 1 & - & 2 & 3 & \\
\hline & Asit-Baz & 1 & - & 2 & 3 & \\
\hline & Çözeltiler ve Fiziksel Özellikleri & 1 & - & 1 & 2 & \\
\hline Lisans & Elektroliz ve Pil & 1 & - & - & 1 & 34.6 \\
\hline & Genel Kimya & 2 & - & - & 2 & \\
\hline & Proteinler & 1 & - & - & 1 & \\
\hline & Isı ve Sicaklık & - & - & 1 & 1 & \\
\hline & Elektrokimya & - & - & 1 & 1 & \\
\hline & Termodinamik & - & - & 1 & 1 & \\
\hline & Çevre Bilimi & 1 & - & 1 & 2 & \\
\hline & Biyoloji & 1 & - & - & 1 & \\
\hline & $\begin{array}{l}\text { Manyetizma } \\
\text { Elektrik }\end{array}$ & - & - & 1 & 1 & \\
\hline & Elektrik & - & - & 1 & 1 & \\
\hline
\end{tabular}

(M: Makale, Y: Yüksek Lisans Tezi, D: Doktora Tezi) 
Tablo 3'e bakıldığında PDÖ yaklaşımı ile ilgili tercih edilen grubun en fazla lisans düzeyi eğitim alan adaylardan oluştuğu (\%34.6) ve bu adaylarla laboratuvar ( $\mathrm{f}=6)$ uygulama dersleri kapsamında çalışıldığ saptanmıştır. Ortaokul 6. sınıf öğrencileri ikinci en çok tercih edilen grup (\%24.7) ve bu öğrencilerle en fazla çalışılan konu ise Madde ve Isı 'ünitesi olarak tespit edilmiştir. 12.sınıf öğrenci grubuyla herhangi bir çalışma yapılmamıştır. Çalışmaların ortaokul ve özellikle lisans öğrencileri üzerinde yoğunlaştığı saptanmıştır.

\section{SONUÇ VE TARTIŞMA}

Araștırmanın hedeflenen amacından yola çıkılarak 2010-2020 yılları arasında PDÖ yaklaşımı ile ilgili yapılmış yüksek lisans, doktora tezleri ve makaleler yayın yılı, yayın türü, araştırma yöntemi, örneklem grubu, işlenen ünite-konu ve ölçme aracı gibi belirli kriterler doğrultusunda incelemeye alınmıştır. Fen bilimleri eğitiminde PDÖ ile ilgili çalışmaların yılların içerisinde artış ve azalış gösterdiği belirlenmiştir. Yıllar içerisinde yayın türlerinin değişimleri incelendiğinde; 2010 ve 2013 yıllarında PDÖ ile ilgili en fazla yayın yapıldığı, bunların yüksek lisans ve makale yayın türü olduğu tespit edilmiştir. 2011 ve 2014 yıllarının bu yaklaşımla ilgi en az yayının yapıldığı gözlenmiştir. 2012 ve 2013 yıllarında en fazla olmak üzere doktora çalışmalarında PDÖ tercih edilmekle birlikte 2018-2019 y1llarında PDÖ ile ilgili herhangi bir doktora çalışmasına rastlanılmamıştır. Yapılan analizler sonucunda ulaşılan bulgulardan bir diğeri ise PDÖ çalışmalarında nicel araştırma yönteminin daha fazla tercih edilmekle birlikte en fazla 2010 yılında nicel araştırmaların gerçekleştirildiği, bu yayınların da yüksek lisans tezleri ve makalelerde olduğu görülmektedir. Literatür tarandığında farklı araştırmalarda nicel araştırma yönteminin tercih edildiği görülmekle birlikte bu araştırmada elde edilen bulguları da destekler niteliktedir. (Çiltaş, Güler, \& Sözbilir, 2012; Göktaş, Hasancebi, Varışlıoğlu ve Akçay, 2012; Gülbahar ve Alper, 2009; Sert, Kurtoğlu, Akıncı \& Seferoğlu, 2012; Sözbilir \& Kutu, 2008; Ulutaş ve Ubuz, 2008). Bunun yanında çalışmalarda nitel araştırmaların çok fazla tercih edilmediği sonucuna varılmış ve bu konuda da literatür incelendiğinde bu bulguya ulaşmış benzer çalışmaların olduğu görülmüştür (Çiltaş vd., 2012; Ulutaş ve Ubuz, 2008).

Nitel araştırmalardan ziyade araştırmacılar tarafından nicel araştırma yönteminin tercih edilmesinin nedeni olarak; sayısal verilerin analizlerinin yapılarak somut bulgulara ulaşılmasının daha kolay olması diğer yandan çalışmadan elde edilen sonuçların genellenebilmesi, örneklem sayısının fazla olabilmesi, ve maliyet giderlerinin daha az olmasının etken olabileceği söylenebilir (Göktaş vd.,2012). Karma araştırma deseninin doktora çalışmaları başta olmak üzere yüksek lisans tezlerinde tercih edildiği görülmektedir. PDÖ ile ilgili yapılmış çalışmalarda örneklem grubu olarak daha çok ortaokul öğrencilerinden 5,6 . ve 7. sınıf öğrencilerinin oluşturduğu görülmektedir. Bunu takiben lisans düzeyinde ki öğrencilerin de çalışmalara dahil edildiği saptanmıştır.12. sınıf öğrencileri bu süreçlere dahil edilmemiştir. Bunun sebebi olarak bu öğrencilerin yükseköğretime geçiş sınavlarına hazırlanmasından kaynaklandığı düşünülmektedir. Araştırmalarda ağırlıklı olarak 6. sınıf düzeyinde 'Madde ve 1sı' ve "Maddenin tanecikli yapısı" konuları üzerinde çalışmalar yapılmıştır. Bunun yanında lisans öğrencileriyle laboratuvar uygulamaları konusu ikinci en çok tercih edilen konu olarak saptanmıştır. Yapılan araştırmalarda veri toplama aracı olarak en çok tercih edilenler başarı testi ve tutum ölçeği olarak belirlenmiştir. Araştırmacıların ağırlıklı olarak nicel araştırma yöntemini kullanmaları sebebiyle bu veri toplama araçlarına yöneldiklerini söylenebilir. Bunun yanı sıra görüşme formlarının da daha fazla tercih edildiği saptanmıştır. Tespit edilen bu durum benzer diğer çalışma sonuçlarıyla örtüşmektedir (Temel vd.,2014; Yavuz,2017). Test ve ölçeklerin daha ağırlıklı kullanıldığı bunların dışında farklı olarak problem senaryosu gibi veri toplama araçlarıda çalışmalarda kullanılmıştır. Elde edilen 
sonuçlardan yola çıkılarak aşağıdaki önerilerde göz önünde bulunabilir; Son yıllarda PDÖ ile ilgili yayın türlerinin sayısı artırılabilir. Çalışmalarda daha fazla nicel araştırma yöntemi kullanıldı ̆̆ı belirlenmiști, diğer araştırma yöntemlerinin kullanılabilirliğinin arttırılması sağlanabilir. PDÖ yaklaşımında kullanılan veri toplama araçları çeşitliliği artırılarak araştırma konusuna farklı boyutların getirilebileceği düşünülebilir.

\section{KAYNAKÇA}

Aysu, G. Probleme dayal öğrenme tabanl stem uygulamalarının ögrrencilerin akademik başarılarına ve ögrendikleri bilgilerin kalıcllı̆̆na etkisinin incelenmesi. Niğde: Ömer Halis Demir Üniversitesi, Eğitim Bilimleri Enstitüsü, Yüksek Lisans Tezi ,2019.

Barrows, H.S. (1996). Problem-based learning in medicine and beyond: A brief overview. New Directions for Teaching and Learning, 68, 3-11.

Çiftçi, S., Meydan, A., Ektem, I. S. (2005), Sosyal bilgiler öğretiminde probleme dayalı öğrenmeyi kullanmanın öğrencilerin başarısına ve tutumlarına etkisi. http://dergisosyalbil.selcuk.edu.tr/susbed/article/view/476 adresinden 10 Nisan 2020 tarihinde alınmıştır.

Çiltaş, A., Güler, G., \& Sözbilir, M. (2012). Mathematics education research in Turkey: A content analysis study. Educational Sciences: Theory \& Practice, 12(1), 574-578.

Gülbahar, Y. \& Alper, A. (2009). Öğretim teknolojileri alanında yapılan araştırmalar. Ankara Üniversitesi Ĕgitim Bilimleri Fakültesi Dergisi 42(2), 93-111

Göktaş, Y., Hasançebi, F., Varışoğlu, B., Akçay, A., Bayrak, N., Baran, M., \& Sözbilir, M. (2012). Trends in educational research in Turkey: A content analysis. Educational Sciences: Theory \& Practice, 12(1), 455459.

Göktaş, Y., Küçük, S., Aydemir, M., Telli, E., Arpacık, Ö., Yıldırım, G., Reisoğlu, İ. (2012). Türkiye’ de eğitim teknolojileri araştırmalarındaki eğilimler: 2000-2009 dönemi makalelerinin içerik analizi. Kuram ve Uygulamada Ĕgitim Bilimleri Dergisi, 12(1), 406-443.

Kaptan, F., ve Korkmaz, H. (2001). Fen eğitiminde probleme dayalı öğrenme yaklaşım. Hacettepe Üniversitesi Eğitim Fakültesi Dergisi. 20,191-192

Kılınç, A. (2007). Probleme dayalı öğrenme. Kastamonu Eğitim Dergisi. 15 (2), 561 - 578

Koyuncu, M. S., Şata, M., Karakaya, İ. (2018). Eğitimde ölçme ve değerlendirme kongrelerinde sunulan bildirilerin doküman analizi yöntemi ile incelenmesi. Eğitimde ve Psikolojide Ölçme ve Değerlendirme Dergisi, 9(2), 216-238.

Lehtinen, E. (2002). Developing models for distributed problem-based learning: theoretical and methodological reflection. Distance Education, 23 (1), 109-117.

Saban, A. (2004). Ö̆grenme-öğretme süreci. yeni teori ve yaklaşımlar. Üçüncü Baskı. Ankara: Gazi Kitabevi

Sert, G., Kurtoğlu, M., Akıncı, A. ve Seferoğlu, S. S. (2012). Öğretmenlerin teknoloji kullanma durumlarını inceleyen araştırmalara bir bakış: bir içerik analizi çalışması, Akademik Bilişim, 1-3 Şubat 2012, Uşak Üniversitesi, Uşak.

Söyleyici, H. Probleme dayal ögrrenmenin ortaokul öğrencilerinin bilimsel süreç becerilerine, tutumlarına ve başarılarına etkisinin incelenmesi: Işılk Ünitesi Örneği. Edirne: Trakya Üniversitesi, Fen Bilimleri Enstitüsü, Yüksek Lisans Tezi,2018.

Sözbilir, M. \& Kutu, H. (2008). Development and current status of science education research in Turkey. Essays in Education, Special Issue, 1-22, http://www.usca.edu/essays/specialedition/ MSozbilirandHulyaKutu.pdf adresinden 20 Nisan 2020 tarinde alınmıştır.

Şahin, A. (2011). Genel fizik laboratuvar dersinde basit elektrik devreleri konusunun ögrretilmesinde probleme dayalı öğrenme (pdö) yaklaşımının öğrencilerin akademik başarılarına etkisinin incelenmesi. Erzurum: Atatürk Üniversitesi, Eğitim Bilimleri Enstitüsü, Yüksek Lisans Tezi. 
Şendağ, Serkan. (2008). Çevrimiçi probleme dayalı öğrenmenin öğretmen adaylarının eleştirel düşünme becerilerine ve akademik başarılarına etkisi. Doktora Tezi, Anadolu Üniversitesi, Eğitim Bilimleri Enstitüsü, Eskişehir.

Temel, S., Şen, Ş., Yılmaz, A. (2014). Fen eğitiminde probleme dayalı öğrenme ile ilgili yapılan çalışmalara ilişkin bir içerik analizi: türkiye örneği. K. Ü. Kastamonu Eğitim Dergisi, 23 (2), 565-580.

Ulutaş, F., ve Ubuz, B. (2008). Matematik eğitiminde araştırmalar ve eğilimler: 2000 ile 2006 y1lları arası. Ilköğretim Online, 7(3), 614-626.

Uluyol, Ç. (2009). Problem temelli öğrenmenin öğrenci başarısına etkisi ve öğrenci görüşlerinin değerlendirilmesi. Gazi Eğitim Fakültesi Dergisi, 29 (1), 19-36.

Yavuz, G., Yavuz, S. (2017). Fen eğitiminde proje tabanlı öğretimle ilgili tezlerin içerik analizi: türkiye örneği (2002-2014). Mehmet Akif Ersoy Üniversitesi Eğitim Fakültesi Dergisi. 43, 255-282.

Yıldırım, A. ve Şimşek, H. (2013). Sosyal bilimlerde nitel araştırma yöntemleri, Seçkin Yayıncılık, Ankara.

Walcott, H. F. (1994). Transforming Qualitative Data: Description, Analysis and Interpretation. London: SAGE Publications. 


\section{EXTENDED ABSTRACT}

\section{The Investigation of Scientific Studies Regarding Problem Based Learning Approach in the Field of Science Education}

Science course contents cover many events we encounter in our daily lives. Students are expected to find solutions to the problems they encounter in their lives by using the information they have acquired in the science curriculum in their schools. Nowadays, instead of the traditional approach where the teacher is the active contributor, approaches where students are more active and teachers act as guides are more commonly and efficiently used in science education (Söyleyici, 2018). Problem-based learning approach is one of such approaches. In the problem-based learning approach, it is aimed to teach the students the methods they can use to produce solutions for the problems they encounter. Students are the focal point in the problem-based learning approach. Students work as groups to come to a solution with the guidance of the teacher. On the other hand, students improve their investigation and critical thinking skills. Environments where students obtain the information by themselves are created (Barrows 1996). It was revealed that the problem-based learning approach greatly improved the students' ability to find solutions to the problems they faced while also helping the student profile playing an active role in the classroom (Kaptan \& Korkmaz, 2001). Based on the benefits of such an approach which occupies an important position in the education system; Examination of the studios on problem-based learning approach using descriptive analysis and the results to be obtained at the end of this examination should allow people who is to work in this field to open new doors while having knowledge of content of the subject (Temel, Şen \& Y1lmaz, 2014). For this purpose, a literature review study has been carried out in order to determine the studies conducted in science education in our country on the basis of problembased learning at primary, secondary, high school and undergraduate levels. For this study, in the field of problem based learning for science education; master's theses, dissertations found on the databases of National Thesis Center of the Council of Higher Education, TR Index and Google Scholar and essays published between 2010-202 on science education with its sub-units physics, chemistry and biology have been scrutinized in line with the determined criteria. All the publications reviewed within the scope of this study have been examined in line with the criteria such as the type of publication, sample group selected, research method, the unit and subject treated, data collection tools preferred in the research and the year of publication. As the result of this literature review, 40 master's theses, 15 dissertations and 29 essays written on the subject of problem-based learning approach in science education with its sub-units' physics, chemistry and biology, have been taken into consideration. In the study, data was collected through document analysis, which is one of the qualitative research methods. For the analysis of data, descriptive analysis method is utilized and the process is completed with the help of percentage and frequency calculations. Document review involves the analysis of written products related to the situation or situations that are aimed to be investigated (Yildirim \& Şimşek, 2013).

As the result of the study, it is seen that while quantitative research method is the most common method for the publications made on the subject of problem-based learning, mixed research method is mostly preferred in postgraduate and doctoral thesis studies. It is observed that while most of the publications made on this field are master's theses, essays are the second most common type and dissertations are the last. It is seen that while master's theses on this field were most commonly written in 2010 , number of dissertations written on the field was at its highest number in years between 2016-2017 and essays in 2013, and in general, 2010 and 2013 
are the years in which the problem based learning studies were conducted the most. It is observed that while secondary school students studying the subjects of "matter and heat" and "cluster structure of matter" were the most preferred study group in problem-based learning studies, graduate students studying the "lab education" subject were also often chosen as a sample group. In these studies, it was concluded that while success tests and attitude scales were used more frequently as measurement tools, various data collection tools are preferred. 